\title{
Planejamento e gestão ambiental na Universidade Federal da Paraíba, Nordeste do Brasil: análise e contribuições
}

\author{
Dimítri de Araújo Costa ${ }^{1 *}$, Gilivã Antonio Fridrich', Randolpho Sávio \\ de Araújo Marinho', Marcos Paulo Gomes Pinheiro', João Carlos de \\ Miranda e Silva ${ }^{1}$, Marcos Leonardo Ferreira dos Santos ${ }^{1}$, Artur \\ Henrique Freitas Florentino de Souza ${ }^{1,2}$, Maria Cristina Crispim ${ }^{1,3}$
}

${ }^{1}$ Programa de Pós-Graduação em Desenvolvimento e Meio Ambiente. Centro de Ciências Exatas e da Natureza. Universidade Federal da Paraíba. Campus I. João Pessoa-PB. Brasil (CEP 58051-900).*E-mail: costa.researcher@yahoo.com.br.

${ }^{2}$ Universidade Federal do Piauí. Departamento de Biologia. Campus Senador Helvídio Nunes de Barros. Rua Cícero Duarte, 905. Bairro Junco. Picos-PI. Brasil (CEP 64670-067).

${ }^{3}$ Universidade Federal da Paraíba. Centro de Ciências Exatas e da Natureza. Departamento de Sistemática e Ecologia. Campus I. João Pessoa-PB. Brasil (CEP 58051-900).

Resumo. Os problemas ambientais têm-se agravado nos últimos anos em decorrência do aumento na extração, produção, consumo e descarte, e à medida que os seres humanos interveem na natureza aumentam os conflitos por recursos, o que mostra a necessidade de se manter um equilíbrio entre o homem e a natureza. Nesse contexto, surge a gestão ambiental como gerência do relacionamento entre o ser humano e o meio ambiente a fim de minimizar os impactos. Desta forma, ações são necessárias visando à minimização de tais impactos em vários segmentos, inclusive nas universidades. A Universidade Federal da Paraíba possui um Plano de Gestão de Logística Sustentável (PGLS), elaborado em 2013, por sua Comissão de Gestão Ambiental (CGA), contemplando material de consumo, energia elétrica, água e esgoto, coleta seletiva, qualidade de vida no ambiente de trabalho, compras e contratações, e deslocamento de pessoal. Apesar da irrefutável importância das propostas contidas no Plano, é detectada uma lacuna na ausência de temas relevantes. O objetivo deste trabalho é analisar as propostas do Plano de Gestão Ambiental da UFPB e propor ações que venham a complementá-lo. São propostos: 1) um projeto de acessibilidade para melhoria na mobilidade humana de pessoas com deficiência; 2) um programa de manejo dos resíduos orgânicos por meio da compostagem, sendo seu produto aproveitado como fertilizante e utilizado na universidade como solução viável e ecológica, juntamente com a implantação de uma empresa júnior para gerir esse processo; 3 ) a inclusão de medidas quanto aos mosquitos vetores por meio de busca e eliminação de focos, monitoramento da ocorrência, bem como a sensibilização das pessoas por meio de educação ambiental; e 4) uma proposta de zoneamento por meio da espacialização das informações do uso e ocupação do solo.
Recebido:

03/08/2017

Aceito:

08/11/2017

Publicado:

31/12/2017

Acesso aberto Artigo completo

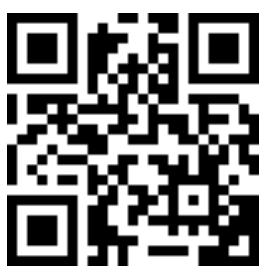

ORCID

(1) 0000-0002-5399-2483 Dimítri de Araújo Costa

(ㄱ) 0000-0003-1057-5134 Gilivã Antonio Fridrich

(D) 0000-0001-8303-0819 Randolpho Sávio de Araújo Marinho

(D) 0000-0002-8465-6570

Marcos Paulo Gomes Pinheiro 
Palavras-chave: Acessibilidade; Compostagem; Empresa júnior; Mosquitos vetores; Zoneamento.

\begin{abstract}
Planning and environmental management at the Federal University of Paraiba, Northeast Brazil: analysis and contributions. Environmental problems have worsened in recent years as a result of increased extraction, production, consumption and disposal, and as humans intervene in nature, resource conflicts increase, which shows the need to maintain a balance between man and nature. In this context, environmental management emerges as a management of the relationship between the human and the environment in order to minimize impacts. In this way, actions are necessary in order to minimize such impacts in several segments, including in universities. The Federal University of Paraíba has a Sustainable Logistics Management Plan (PGLS), prepared in 2013, by its Environmental Management Committee (CGA), covering material for consumption, electricity, water and sewage, selective collection, quality of life in the work environment, purchases and signings, and staff's displacement. Despite the irrefutable importance of the proposals contained in the plan, a gap is detected in the absence of relevant issues. The objective of this work is to analyze the proposals of the Environmental Management Plan of the UFPB and propose actions that will complement it. The following are proposed: 1) an accessibility project to improve the human mobility of people with physical disabilities; 2) a program of management of organic waste through composting, its product being used as fertilizer and used in the university as a viable and ecological solution, together with the implementation of a junior company to manage this process; 3) the inclusion of measures regarding mosquitoes vector through search and elimination of foci, monitoring of occurrence, as well as the sensitization of people through environmental education; and 4) a proposal of zoning through spatialization of information on land use and occupation.
\end{abstract}

Keywords: Accessibility; Composting; Junior company; Mosquitoes vector; Zoning.

\section{Introdução}

A gestão ambiental é compreendida como a gerência do relacionamento entre 0 ser humano e o meio ambiente. Segundo Barbieri (2004), os problemas ambientais nem sempre foram tão evidentes, mas têm sido agravados pelo homem em decorrência do aumento da escala de extração, produção, consumo e descarte inadequado de resíduos no ambiente.

À medida que aumenta a intervenção humana na natureza também crescem os conflitos pelo uso dos recursos, isto se tem intensificado nos últimos 30 anos. Portanto, mais do que nunca, precisa-
(ㄷ) 0000-0001-5979-6451 João Carlos de Miranda e Silva

(1) 0000-0003-0521-6137 Marcos Leonardo

Ferreira dos Santos

(1) 0000-0002-9069-7950

Artur Henrique Freitas

Florentino de Souza

(D) 0000-0002-4414-2989

Maria Cristina Crispim 
de redemocratização do país na década de 1980. Com a promulgação da Lei $n^{\circ}$ 6.938/1981, que dispõe sobre a Política Nacional do Meio Ambiente, já manifestava uma maior preocupação com os recursos ambientais do País (Brasil, 1981). Posteriormente, um capítulo inteiro (Capítulo VI) na Constituição de 1988 (Brasil, 1988), reforçaram ainda mais essa preocupação.

Em uma abordagem organizacional, têm-se então as ações dos governos, órgãos públicos, empresas, organizações nãogovernamentais (ONGs), entre outros, que desenvolvem diversas políticas, programas, projetos e estratégias de gestão ambiental.

Nas universidades brasileiras, a implementação de programas de gestão ambiental é recente. Na Universidade Federal da Paraíba (UFPB), por exemplo, existe desde 2013, uma comissão para tratar de assuntos exclusivos de gestão ambiental, a Comissão de Gestão Ambiental/UFPB, criada através da Portaria R/GR $\mathrm{n}^{\circ}$ 427/2013, tendo em seu corpo estrutural professores, alunos bolsistas e voluntários, além de um servidor técnico administrativo. Sua principal função é o auxílio à reitoria no diagnóstico e formulação de estratégias de enfrentamento do passivo ambiental da instituição, mediante a elaboração de programas de gestão ambiental (UFPB, 2017).

Algumas propostas que fogem do tradicional, como a gestão resíduos sólidos, economia de água e energia, bem como a diminuição da geração de efluentes, precisam ser elaboradas para uma contínua melhoria da gestão ambiental. A educação ambiental é destaque, não só para o público que faz parte desses sistemas e programas, mas também para que se propague a ideia e que os projetos de gestão ambiental tenham êxito, sendo colocados em prática por todos que fazem parte do contexto da instituição.

Atualmente, a sustentabilidade é um tema dominante. Está na academia, no ambiente de trabalho, nos noticiários, nos comerciais, nos jornais e revistas, nas conversas diárias. É difícil encontrar algum posicionamento contrário ao tema, já que existe consenso de que a sustentabilidade é algo bom, embora alguns a considerem uma utopia (Keinert, 2007).

Portanto, a gestão ambiental deve ter como foco metas que convergem para a sustentabilidade (Coelho et al., 2017) e na universidade não poderia ser diferente.

Como propostas, além das apresentadas no plano de gestão elaborado pela Comissão de Gestão Ambiental da UFPB, pode-se explorar lacunas que continuam a fazer parte do cotidiano da comunidade que faz uso da instituição, seja ela acadêmica, funcionários e comunidades circunvizinhas, as quais também utilizam serviços do Campus I, em João Pessoa-PB.

Neste artigo propõe-se inserir no Plano de Gestão da UFPB temas que não foram abordados pela Comissão de Gestão Ambiental, tais como a acessibilidade, a compostagem dos resíduos orgânicos, o manejo dos mosquitos vetores e o zoneamento ambiental.

Tudo isso pode ser bem embasado utilizando a educação ambiental, que é a base da gestão ambiental, nenhuma comissão por mais completa que seja, por mais propostas e planos que tenha, pode lograr êxito sem a conscientização de todos e assim realmente mudar a mentalidade das pessoas sobre a importância da causa socioambiental.

Com base no Plano de Gestão de Logística Sustentável da Universidade Federal da Paraíba e o seu respectivo Relatório Preliminar, foi realizada a proposta para acrescentar os seguintes temas, i.e. acessibilidade, compostagem dos resíduos orgânicos, manejo dos mosquitos vetores e zoneamento.

\section{Área de estudo}

$\mathrm{O}$ estudo foi realizado na Universidade Federal da Paraíba (Campus I), localizada entre as coordenadas de referência $07^{\circ} 08^{\prime} 41^{\prime \prime} \mathrm{S} / 34^{\circ} 51^{\prime} 02^{\prime \prime} \mathrm{W}$ e $07^{\circ} 07^{\prime} 54 \mathrm{~S} / 34^{\circ} 50^{\prime} 31^{\prime}$ ' W, no Município de João Pessoa, Estado da Paraíba, Brasil (Figura 1). 


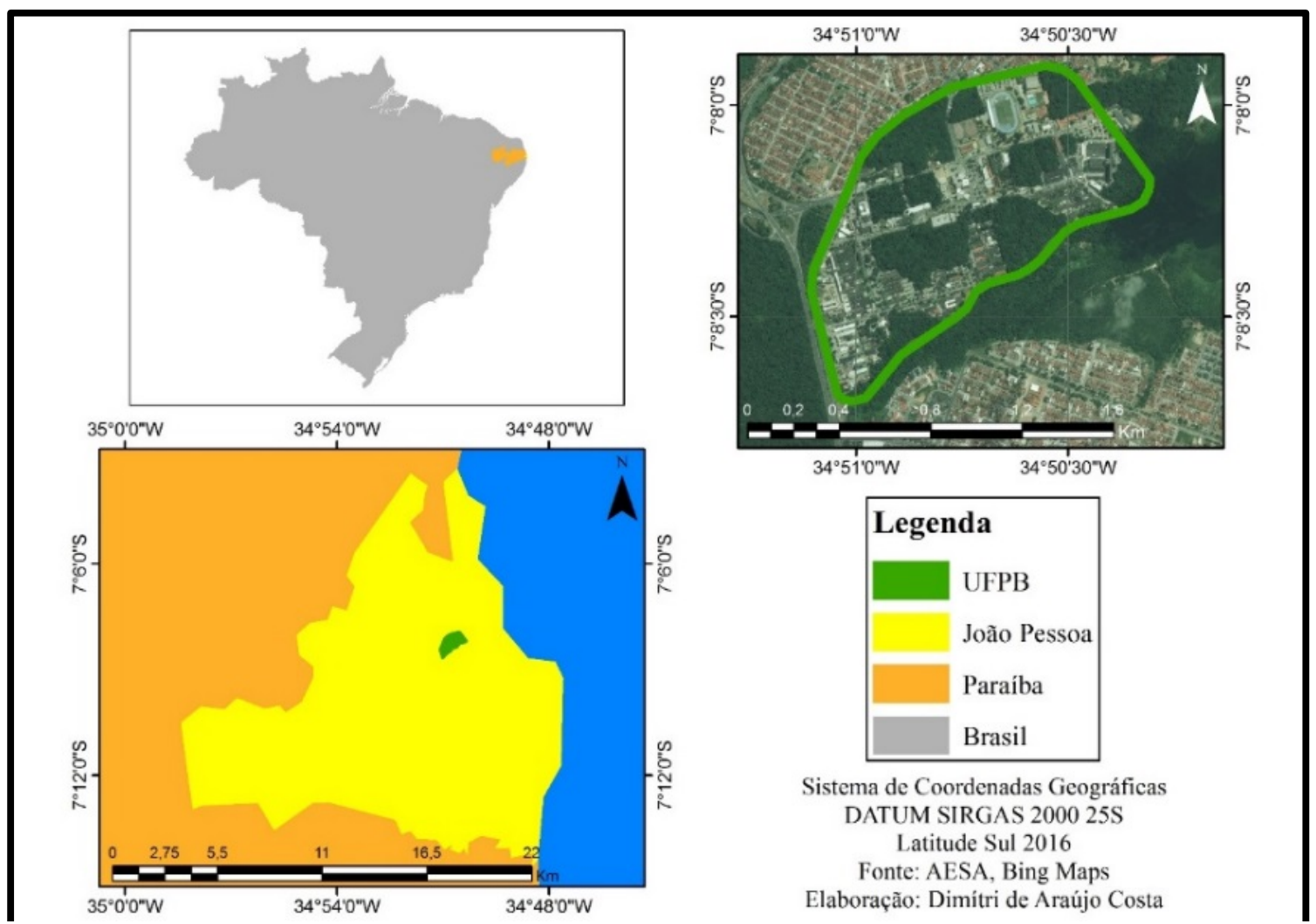

Figura 1. Mapa de localização da Universidade Federal da Paraíba (Campus I), Município de João Pessoa, estado da Paraíba, Brasil. (Fonte: Adaptado de AESA, 2016; e Bing Maps, 2016).

\section{Plano de Gestão de Logística Sustentável (PGLS)/UFPB}

Em setembro de 2013, a Comissão de Gestão Ambiental da Universidade Federal da Paraíba elaborou o Plano de Gestão de Logística Sustentável (PGLS), estabelecendo critérios, práticas e diretrizes para a promoção do desenvolvimento sustentável nacional nas contratações realizadas no Campus I localizado no Município de João Pessoa.

O conjunto de leis e normas que regulamentam o uso racional dos recursos naturais, bem como o gerenciamento de resíduos e rejeitos e o estímulo a práticas de sustentabilidade são a Política Nacional de Meio Ambiente (Lei no 6.938/1981) (Brasil, 1981), a Política Nacional de Recursos Hídricos (Lei no 9.433/1997) (Brasil, 1997), a Agenda Ambiental na Administração
Pública - A3P (Portaria MMA $\mathrm{n}^{\circ}$ 510/2002), a Política Nacional de Resíduos Sólidos (Lei n 12.305/2010) (Brasil, 2010), licitações sustentáveis (Lei ${ }^{\circ}$ 12.349/2010 e Decreto $n^{\circ}$ 7.746/2012), a Instrução Normativa MPOG $n^{0} 1 / 2010$, que trata dos critérios de sustentabilidade ambiental na aquisição de bens, contratação de serviços ou obras pela Administração Pública Federal direta, autárquica e fundacional, bem como e especialmente a Instrução Normativa MPOG $n^{0}$ 10/2012, que estabelece as regras para elaboração dos planos de logística sustentável.

Diante deste contexto, surge a demanda para a elaboração do Plano de Gestão de Logística Sustentável da Universidade Federal da Paraíba (PGLS/UFPB) que foi estruturado em cinco etapas, sintetizadas no Fluxograma abaixo (Figura 2). 


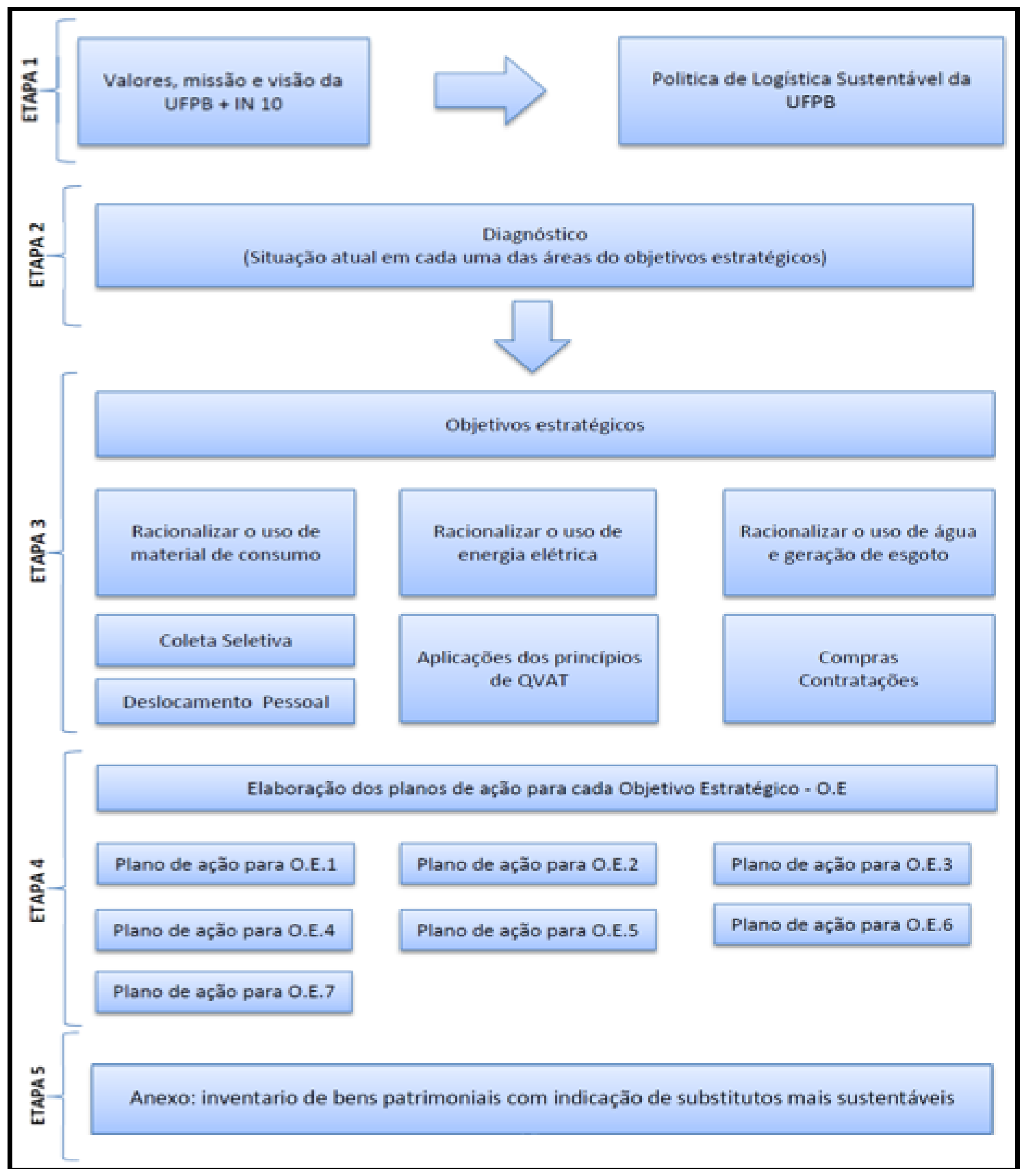

Figura 2. Esquema do Plano de Logística Sustentável. Fonte: Adaptado de CGA (2013).

Na primeira etapa deste plano de gestão, foi feita uma análise da missão, da visão e dos valores institucionais estabelecidos pela Universidade Federal da Paraíba, em seu Plano de Desenvolvimento Institucional (2009-2012), e do cotejamento com os requisitos da Instrução Normativa MPOG $n^{0} 10 / 2012$. Foram mencionados sete pontos principais, englobando as seguintes áreas: 1) Material de consumo; 2)
Energia elétrica; 3) Água e esgoto; 4) Coleta seletiva; 5) Qualidade de vida no ambiente de trabalho; 6) Compras e contratações; e 7) Deslocamento de pessoal. $\mathrm{Na}$ etapa seguinte, foi realizado, através de pesquisa documental, visita in loco e aplicação de entrevista com responsáveis pelos setores envolvidos, um diagnóstico da situação atual. 
Na terceira etapa, com base no diagnóstico realizado anteriormente, foram traçados sete objetivos estratégicos pelo PGLS/UFPB (CGA, 2013):

Objetivos Estratégicos (O.E.):

O.E. 1 - Estabelecer práticas de sustentabilidade e de uso racional para material de consumo;

O.E. 2 - Estabelecer práticas de sustentabilidade e de uso racional para nortear o consumo de energia elétrica; O.E. 3 - Estabelecer práticas de sustentabilidade e de uso racional para consumo de agua e geração de esgoto; O.E. 4 - Estabelecer práticas de sustentabilidade no fortalecimento do programa de coleta seletiva;

O.E. 5 - Promover o fortalecimento dos programas de qualidade de vida no ambiente do trabalho;

O.E. 6 -Estabelecer práticas de sustentabilidade nos processos de compras e

Contratações;
O.E. 7 - Estabelecer práticas de sustentabilidade e uso racional para atividades concernentes com o deslocamento de pessoal.

A etapa 4 foi constituída dos planos de ação que compõem o Plano de Logística Sustentável, segmentado por objetivo estratégico, e a etapa 5 do inventário de bens patrimoniais.

\section{Relatório preliminar do PGLS/UFPB}

Em 2015, foi elaborado o relatório do Plano de Gestão de Logística Sustentável, que abrangeu o período de outubro de 2013 a março de 2014 (CGA, 2015). Este relatório visa atender ao requisito estabelecido no artigo 13, da Instrução Normativa MPOG n ${ }^{0} 10 / 2012$. A metodologia de formulação do Plano de Logística Sustentável adotado pela UFPB seguiu os passos descritos no Fluxograma a seguir (Figura 3).

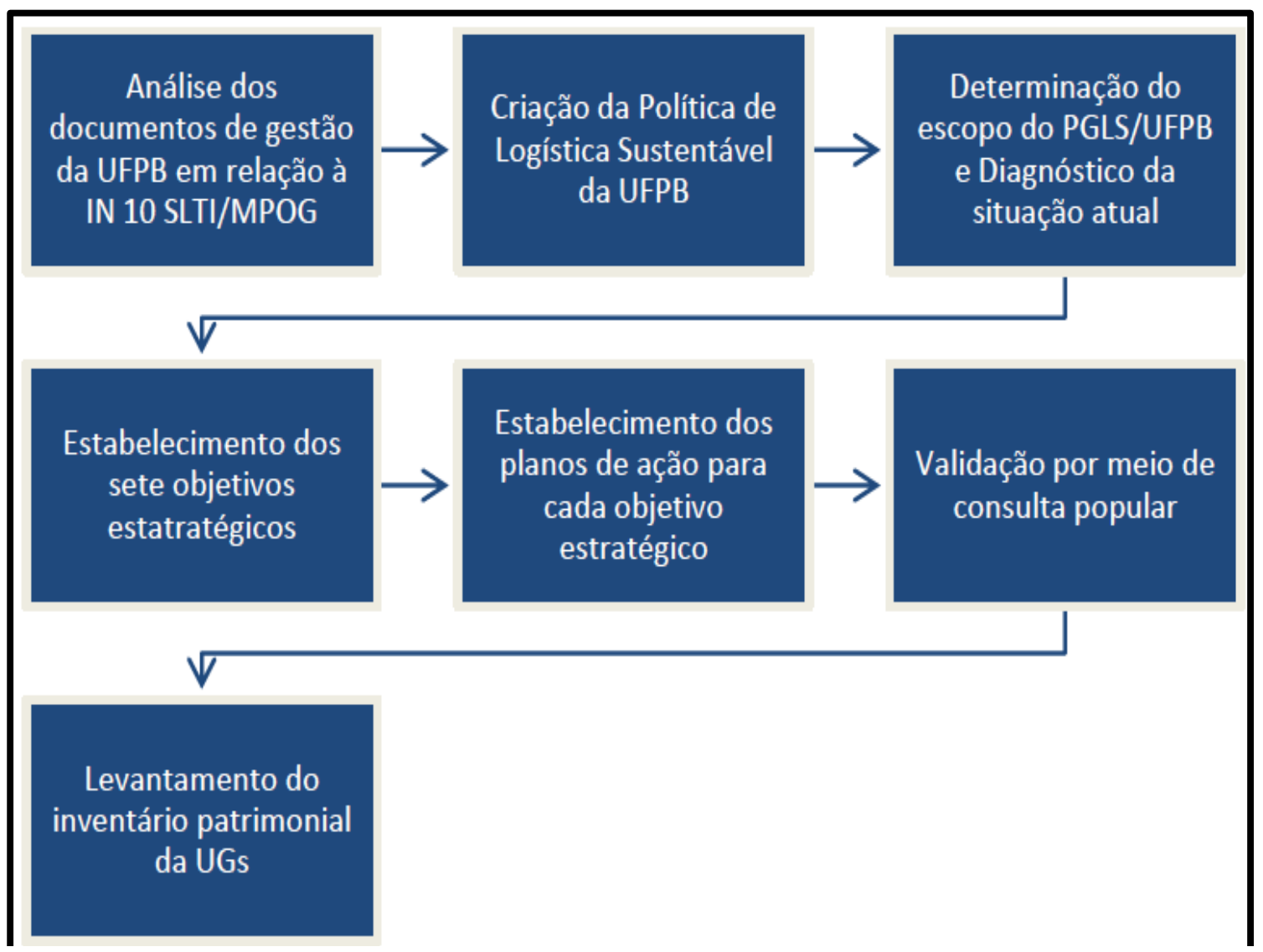

Figura 3. Metodologia de formulação do PGLS/UFPB. Fonte: Adaptado de CGA (2015). 
Dada à complexidade da operacionalização da Instrução Normativa MPOG $n^{0}$ 10/2012, foi definido que a confecção do primeiro PGLS/UFPB focaria no atendimento aos requisitos mínimos da IN e no estabelecimento de mecanismos de sistematização da coleta e tratamento dos dados necessários para a confecção dos relatórios de gestão e que posteriormente de modo gradual, na medida em que os objetivos fossem sendo alcançados, seriam incluídos outros compromissos ambientais mais complexos.

Dentre as sete temáticas propostas no PGLS, cinco foram efetivamente realizadas, i.e. energia elétrica, coleta seletiva (incluindo gestão de resíduos), qualidade de vida no ambiente de trabalho, compras e contrações sustentáveis e deslocamento de pessoal.

\section{na UFPB}

Gestão dos resíduos produzidos

A Comissão de Gestão Ambiental subdividiu os resíduos em 13 categorias, pelo método francês MODECOM, em dois tipos de coletores, verde para recicláveis e azul para orgânicos. Por fim, os resíduos recicláveis foram levados para a Cooperativa Acordo Verde, da Prefeitura Municipal de João Pessoa, onde foram caracterizados e quantificados. Os dados obtidos foram remetidos à Comissão de Gestão Ambiental, responsável pelo monitoramento do Programa de Coleta Seletiva (CGA, 2015).

A cooperativa aproveitou os seguintes materiais: plástico, vidro, papel e metal. Foram coletados um total de $19.397,5 \mathrm{~kg}$ de materiais recicláveis, convertidos em R\$ 5.452,10 (cinco mil e quatrocentos e cinquenta e dois reais e dez centavos) distribuídos entre os membros da Cooperativa Acordo Verde. Os dados indicados são referentes à coleta seletiva do Campus I da UFPB. As outras unidades gestoras como a de Areia, Bananeiras e Rio Tinto, ainda não possuem a Coleta Seletiva Solidária, mas já possuem planos para implantações futuras (CGA, 2015).

Pode-se, então, constatar que o resíduo orgânico (incluindo o resíduo verde), o qual representa 57\% do total, com cerca de $997 \mathrm{~kg}$ produzidos por dia (sendo $132 \mathrm{~kg}$ de resíduo verde), não foi devidamente aproveitado. Desta forma, observa-se a necessidade de aprimorar o manejo deste tipo de resíduo por meio da compostagem, podendo ser utilizado para os mais diversos fins, como produção de adubo orgânico, que pode ser aproveitado na jardinagem/paisagismo presente no Campus I (CGA, 2015).

\section{Qualidade de vida no ambiente de trabalho}

O PGLS/UFPB aborda em uma de suas ações e intervenções práticas, um plano para a melhoria da qualidade de vida no ambiente de trabalho. Esse plano objetiva estabelecer práticas de sustentabilidade para promover 0 fortalecimento dos programas de qualidade de vida no ambiente do trabalho. Propõe ações como, a quantificação dos servidores participantes dos programas e ações voltadas para a qualidade de vida em seu trabalho, em cada ano. Ainda, dentro do campo da Educação Ambiental, outra ação proposta é a utilização de campanhas para a conscientização da comunidade acadêmica sobre a importância desses programas institucionais para a melhoria na qualidade de vida.

De acordo com o relatório preliminar emitido no ano de 2015 do PGLS, foram oferecidas atividades voltadas para a melhoria da qualidade de vida no ambiente de trabalho, i.e., estratégia para o bem-estar no trabalho, programa no enfrentamento ao tabagismo, segurança no trabalho organizacional, relações interpessoais e comportamento profissional, pilates, Tai Chi Chuan, emagrecendo saudável, alimentação saudável, oficina de voz, além de capacitação para o uso de medidas de biossegurança (CGA, 2015).

São ações e programas de grande relevância para a saúde dos servidores da UFPB, contudo não consta nesse planejamento nenhuma ação voltada para pessoas, servidores portadores de deficiência. Desta forma, reforça-se a necessidade da implementação da acessibilidade nos planejamentos futuros da UFPB e uma relação entre todos os centros 
dentro da instituição, para que ocorra uma "facilidade" da implementação e aplicação das propostas da acessibilidade de maneira sustentável.

\section{Resultados e discussão}

\section{Proposta para a inserção da acessibilidade no PGLS/UFPB \\ O planejamento e gestão ambiental} é uma prática recente no âmbito de instituições públicas e privadas. Esse planejamento e gerenciamento faz parte de uma política ambiental, que rege todas as ações realizadas em cada local de atuação profissional, independentemente de seu seguimento.

A gestão ambiental pretende, em
sua configuração, instaurar a
implementação de uma nova cultura e
postura sustentável (a conexão na esfera
ambiental, econômica e social) nos
ambientes de trabalho. Todo o
planejamento e gerenciamento ambiental,
possibilita que os agentes identifiquem
espaços e objetos que não estejam em
acordo com a legislação vigente,
possibilitando a racionalização de custos e
redução do impacto ao meio ambiente.
Sendo assim, a gestão ambiental não busca
somente a organização e a promoção de um
ambiente ecologicamente equilibrado, mas
encarrega-se da melhoria nos ambientes de
trabalho e acesso, possibilitando uma
melhor relação interpessoal, bem-estar e a
mobilidade nesses espaços.

Ao tratar-se de mobilidade/ deslocamento pessoal - acesso universal, pode-se constatar nas propostas e desenvolvimentos de planos de gestão ambiental, que sejam projetados e aplicados para instituições públicas ou privadas (diversos seguimentos), que estes não apresentam de forma explícita e detalhada as questões acerca da acessibilidade, sejam elas, tanto para a mobilidade humana (deficiência física), quanto para acessibilidade de pessoas com dificuldades sensoriais e mentais. Portanto, configura-se a necessidade da inserção nos planejamentos e gestão ambiental, projetos, ações de acessibilidade em todas as instituições, citam-se como exemplo,
Instituições de Ensino Superior, por haver um público de usuários diversificados.

Sabe-se que o ser humano está inserido no meio ambiente, como um ser social que interage com o meio. Porém, por possuir essa interação, acaba segregando os espaços e dificultando a vivência de indivíduos da mesma espécie. Entretanto, é percebido atualmente que há uma mudança de pensamento social, em que a espécie humana está se preocupando com os espaços de vivência, convívio e sua acessibilidade no âmbito universal.

Essa temática da acessibilidade não se configura somente no caso da mobilidade, com o direito de ir e vir garantido no art. $5^{\circ}$, da Carta Magna de 1988 (Brasil, 1988), mas também ao acesso a diversos meios de comunicação e interação pessoal seja no campo perceptivo, sensorial e cognitivo. O desenvolvimento da acessibilidade, dentro da ideia de projetar um ambiente mais abrangente $\mathrm{e}$ menos restritivo, tem-se tornado uma tendência mundial e irreversível que garante a melhoria na qualidade de vida do ser humano.

A acessibilidade é entendida como a possibilidade que um indivíduo tem de compreender e interagir com o espaço urbano, bem como comunicar-se com outros cidadãos, tendo ou não limitações de mobilidade ou percepção sensorial. Um espaço acessível possibilita ao acesso a edificações, ao meio urbano, a transportes, à comunicação e aos serviços, o que mostra que um espaço acessível é direito de todos. Como tal esse deve ser vivenciado e utilizado por qualquer pessoa independentemente do tipo de acesso que necessitar (Nunes et al., 2007).

Já o entendimento da Lei $\mathrm{n}^{\circ}$ 13.146/2015 (Brasil, 2015), no seu art. $3^{\circ}$, diz que para fins de aplicação desta lei, consideram-se:

I - acessibilidade: possibilidade e condição de alcance para utilização, com segurança e autonomia, de espaços, mobiliários, equipamentos urbanos, edificações, transportes, informação e comunicação, inclusive seus sistemas e tecnologias, bem como 
de outros serviços e instalações abertos ao público, de uso público ou privados de uso coletivo, tanto na zona urbana como na rural, por pessoa com deficiência ou com mobilidade reduzida;

II - desenho universal: concepção de produtos, ambientes, programas e serviços a serem usados por todas as pessoas, sem necessidade de adaptação ou de projeto específico, incluindo os recursos de tecnologia assistiva;

III - tecnologia assistiva ou ajuda técnica: produtos, equipamentos, dispositivos, recursos, metodologias, estratégias, práticas e serviços que objetivem promover a funcionalidade, relacionada à atividade e à participação da pessoa com deficiência ou com mobilidade reduzida, visando à sua autonomia, independência, qualidade de vida e inclusão social;

IV - barreiras: qualquer entrave, obstáculo, atitude ou comportamento que limite ou impeça a participação social da pessoa, bem como o gozo, a fruição e o exercício de seus direitos à acessibilidade, à liberdade de movimento e de expressão, à comunicação, ao acesso à informação, à compreensão, à circulação com segurança, entre outros, classificadas em:

a) barreiras urbanísticas: as existentes nas vias e nos espaços públicos e privados abertos ao público ou de uso coletivo;

b) barreiras arquitetônicas: as existentes nos edifícios públicos e privados;

c) barreiras nos transportes: as existentes nos sistemas e meios de transportes;

d) barreiras nas comunicações e na informação: qualquer entrave, obstáculo, atitude ou comportamento que dificulte ou impossibilite a expressão ou o recebimento de mensagens e de informações por intermédio de sistemas de comunicação e de tecnologia da informação;

e) barreiras atitudinais: atitudes ou comportamentos que impeçam ou prejudiquem a participação social da pessoa com deficiência em igualdade de condições e oportunidades com as demais pessoas; f) barreiras tecnológicas: as que dificultam ou impedem o acesso da pessoa com deficiência às tecnologias;

A Lei $n^{0}$ 13.146/2015 (Brasil, 2015) dá aos portadores de deficiência, seja ela de qualquer natureza (Tabela 1), o direito a condições de livre acesso a todos os locais, principalmente a instituições educacionais.

Vê-se a importância da implementação da acessibilidade no planejamento e gestão ambiental em Instituições de Ensino, e constatou-se a falta de planejamento e efetivação de ações na UFPB Campus I, acerca da acessibilidade.

Neste sentido, Lira (2014) fomenta que as universidades têm o dever de implementar ações planejadas e eficientes, com vistas a uma educação de qualidade. As pessoas com deficiências e necessidades educativas específicas necessitam de um acesso igualitário ao conhecimento, possibilitando na mediação do processo de ensino/aprendizagem de forma a satisfazer suas necessidades de conhecimentos.

Corroboramos com essas informações acima, quanto à acessibilidade universal nas Instituições de Ensino, independente da modalidade e nível que for. Para reforçar a importância da acessibilidade e sua inserção em planejamentos e gestão ambiental é mensurável que se entenda o seu conceito. O termo acessível compreende o:

[...] espaço, edificação, mobiliário, equipamento urbano ou elemento que possa ser alcançado, acionado, utilizado e vivenciado por qualquer pessoa, inclusive aquelas com a mobilidade reduzida. O termo acessível implica tanto a acessibilidade física como de comunicação (ABNT, 2004).

Analisando o PGLS/UFPB, percebe-se que as propostas das ações desenvolvidas estão voltadas aos princípios sustentáveis, como se configura um plano de gestão ambiental. No entanto, verifica-se que esse planejamento não apresenta dados ou estudos para a elaboração e ou ampliação de espaços de acessibilidade em todo o Campus I, espaços esses, internos e externos, de livre acesso para toda a comunidade estudantil. 
Tabela 1. Definição de deficiência, conforme Decreto nº 5.296/2004, art. 5º Inciso I.

\begin{tabular}{|l|l|}
\hline Deficiência física & $\begin{array}{l}\text { Alteração completa ou parcial de um ou mais segmentos do corpo, acarretando } \\
\text { o comprometimento da função física, apresentando-se sob a forma de } \\
\text { paraplegia, paraparesia, monoparesia, tetraplegia, tetraparesia, hemiplegia, } \\
\text { hemiparesia, ostomia, amputação ou ausência de membro, paralisia cerebral, } \\
\text { nanismo, membros com deformidades congênita ou adquirida, exceto as } \\
\text { deformidades estéticas e as que não possuem dificuldades para o desempenho } \\
\text { de funções. }\end{array}$ \\
\hline Deficiência auditiva & $\begin{array}{l}\text { Perda bilateral, parcial ou total, de quarenta e um decibel (dB) ou mais, aferida } \\
\text { por audiograma nas frequências de 500 Hz, 1.000 Hz, 2.000 Hz e 3.000 Hz. }\end{array}$ \\
\hline Deficiência visual & $\begin{array}{l}\text { Cegueira, na qual a acuidade visual é igual ou menor que 0,05 no melhor olho, } \\
\text { com a melhor correção ótica; a baixa visão, que significa a acuidade visual } \\
\text { entre 0,3 e 0,05 no melhor olho, com a melhor correção ótica; os casos nos } \\
\text { quais a somatória da medida do campo visual em ambos os olhos for igual ou } \\
\text { menor que 60ª } \text { ou a ocorrência simultânea de quaisquer das condições } \\
\text { anteriores. }\end{array}$ \\
\hline Deficiência mental & $\begin{array}{l}\text { Funcionamento intelectual significativamente inferior à média, com } \\
\text { manifestação antes dos dezoito anos e limitação associada a duas ou mais } \\
\text { áreas de habilidades adaptativas, tais como: 1-comunicação; 2-cuidado } \\
\text { pessoal; 3-habilidades sociais; 4-utilização dos recursos da comunidade; 5- } \\
\text { saúde e segurança; 6-habilidades acadêmicas; 7-lazer; 8-trabalho. }\end{array}$ \\
\hline Associação de duas ou mais deficiências. \\
\hline Deficiência múltipla
\end{tabular}

Fonte: Brasil (2004).

A acessibilidade, sendo um tema de extrema relevância e importância social, e o "social” é um dos “tripés" da sustentabilidade, apresenta-se aqui como sugestão e objetivo a inserção e discussão desta temática no planejamento ambiental da UFPB. É essencial analisar as condições estruturais e 0 acesso das pessoas portadoras de deficiência e necessidades especiais (em diferentes níveis) à UFPB/Campus I, por meio da construção, otimização e implementação de políticas públicas da acessibilidade universal no PGLS da referida instituição. Como o planejamento ambiental deve ser participativo, insere-se aqui também propostas de participação da comunidade da Universidade do Campus I.
Para que sejam efetuadas as ações voltadas à acessibilidade, propõem-se os seguintes objetivos e consequentemente, as metas a serem desenvolvidas.

Portanto, este estudo propõe através dos objetivos e metas a serem desenvolvidas, que sejam inseridas ações práticas para a melhoria na mobilidade humana de portadores de deficiência física em espaços acessados pelo público interno e externo e ainda a inclusão e acesso de portadores das demais deficiências.

Para que essas ações ocorram, os projetos de todos os edifícios e espaços dentro da UFPB, devem ser direcionados a fim de promover a integração de toda a comunidade estudantil, com a mobilização de uma equipe inter/transdisciplinar. 
Tabela 2. Proposta de inserção da Acessibilidade no PGLS/UFPB.

\begin{tabular}{|c|c|c|c|c|c|}
\hline Objetivo & Meta & Ações & Responsáveis & Prazo & Indicador De Medida \\
\hline \begin{tabular}{lll} 
Promover & o mapeamento & \multicolumn{2}{c}{} \\
fisico/arquitetônico & e onde \\
encontram-se ações & pontuais de \\
acessibilidade. &
\end{tabular} & $\begin{array}{l}\text { Atingir todos os setores e } \\
\text { centros de estudos, pesquisa e } \\
\text { prestação de serviços da } \\
\text { UFPB, Campus I. }\end{array}$ & $\begin{array}{l}\text { Vistorias e anotações de } \\
\text { todos os espaços utilizados } \\
\text { pelos universitários e } \\
\text { comunidade em geral }\end{array}$ & $\begin{array}{l}\text { Membros } \\
\text { responsáveis dos } \\
\text { centros de estudos } \\
\text { do Campuis I }\end{array}$ & $\begin{array}{l}\text { Primeiro semestre } \\
\text { do ano de aplicação }\end{array}$ & $\begin{array}{l}\text { Elaborar planilhas e mapas de } \\
\text { zoneamentos dos espaços que } \\
\text { apresentam e não acessibilidade }\end{array}$ \\
\hline $\begin{array}{l}\text { Conhecer em quais locais da UFPB } \\
\text { há maior dificuldade para o } \\
\text { desenvolvimento da inclusão das } \\
\text { pessoas com dificuldade. }\end{array}$ & $\begin{array}{l}\text { Atingir todos os setores e } \\
\text { centros de estudos, pesquisa e } \\
\text { prestação de serviços da } \\
\text { UFPB, Campus I. }\end{array}$ & $\begin{array}{l}\text { Através do mapeamento } \\
\text { fisico/arquitetônico aqqui } \\
\text { proposto. }\end{array}$ & $\begin{array}{l}\text { Membros da } \\
\text { Comissão de } \\
\text { Gestão Ambiental }\end{array}$ & $\begin{array}{l}\text { Primeiro semestre } \\
\text { do ano de aplicação }\end{array}$ & Relatórios e imagens dos locais. \\
\hline $\begin{array}{l}\text { Levantar dados sobre a tipologia da } \\
\text { deficiência associada às } \\
\text { possibilidades de acesso ou ausência } \\
\text { de recursos no Camptrs I da UFPB. }\end{array}$ & $\begin{array}{l}\text { Atingir todos os setores e } \\
\text { centros de estudos, pesquisa e } \\
\text { prestą̧ão de serviços da } \\
\text { UFPB, Campus I. }\end{array}$ & $\begin{array}{l}\text { Através do mapeamento } \\
\text { fisioo/arquitetônico aqui } \\
\text { proposto. }\end{array}$ & $\begin{array}{l}\text { Membros } \\
\text { responsáveis dos } \\
\text { centros de estudos } \\
\text { do Campus I }\end{array}$ & $\begin{array}{l}\text { Primeiro semestre } \\
\text { do ano de aplicação }\end{array}$ & $\begin{array}{l}\text { Relatos, mapas de localizações } \\
\text { (zoneamento). } \\
\text { Classificaçăo via documentos } \\
\text { escritos, dos tipos de deficiências } \\
\text { que possuem no Campus I. }\end{array}$ \\
\hline $\begin{array}{l}\text { Conhecer as condiçð̃es de acesso } \\
\text { urbano e equipamento (mobiliário e } \\
\text { materiais) da universidade. }\end{array}$ & $\begin{array}{l}\text { Atingir todos os setores e } \\
\text { centros de estudos, pesquisa e } \\
\text { prestação de serviços da } \\
\text { UFPB, Campus I. }\end{array}$ & $\begin{array}{l}\text { Busca por informaçđ̃es com } \\
\text { os funcionários e usuários } \\
\text { dos setores. }\end{array}$ & $\begin{array}{l}\text { Membros da } \\
\text { Comissão de } \\
\text { Gestão Ambiental }\end{array}$ & $\begin{array}{l}\text { Primeiro e segundo } \\
\text { semestres do ano de } \\
\text { aplicação }\end{array}$ & Relatónios \\
\hline $\begin{array}{l}\text { Promover a construção de uma rede } \\
\text { Inter transdisciplinar dos cursos da } \\
\text { UFPB, para a elaboração de açđes de } \\
\text { acessibilidade no Campus I. }\end{array}$ & $\begin{array}{l}\text { Atingir todos os setores e } \\
\text { centros de estudos, pesquisa e } \\
\text { prestação de serviços da } \\
\text { UFPB, Campus I. }\end{array}$ & $\begin{array}{l}\text { Reunir, organizar e definir } \\
\text { propostas práticas para a } \\
\text { implementação r da } \\
\text { acessibilidade de forma } \\
\text { universal. }\end{array}$ & $\begin{array}{l}\text { Todos os cursos do } \\
\text { Campus I }\end{array}$ & $\begin{array}{l}\text { Primeiro semestre } \\
\text { do ano de aplicą̧ão }\end{array}$ & $\begin{array}{l}\text { Reuniões periódicas, formação da } \\
\text { comissão, elaboraçã̃o do plano de } \\
\text { ação. }\end{array}$ \\
\hline $\begin{array}{l}\text { Investigar programas legais, } \\
\text { programas sociais e rede de apoio, } \\
\text { utilizadas pelas pessoas com } \\
\text { deficiência para acessar o ensino no } \\
\text { ambiente universitário. }\end{array}$ & $\begin{array}{l}\text { Atingir todos os setores e } \\
\text { centros de estudos, pesquisa e } \\
\text { prestação de serviços da } \\
\text { UFPB, Campus I. }\end{array}$ & $\begin{array}{l}\text { Busca por informações com } \\
\text { os funcionários e usuários } \\
\text { dos setores. }\end{array}$ & $\begin{array}{l}\text { Membros } \\
\text { responsáveis dos } \\
\text { centros de estudos } \\
\text { do Campus I }\end{array}$ & $\begin{array}{l}\text { Durante todo o ano } \\
\text { de aplicaçio }\end{array}$ & $\begin{array}{l}\text { Dados quantitativos dos números } \\
\text { desses programas e resultados que } \\
\text { obtiveram. }\end{array}$ \\
\hline $\begin{array}{l}\text { Subsidiar a construção de politicas } \\
\text { públicas na área de ensino públicas } \\
\text { na área do ensino superior da UFPB. }\end{array}$ & $\begin{array}{l}\text { Atingir todos os setores e } \\
\text { centros de estudos, pesquisa e } \\
\text { prestą̧ão de servicọos da } \\
\text { UFPB, Campus I. }\end{array}$ & $\begin{array}{l}\text { Juridico e políticas públicas } \\
\text { da UFPB }\end{array}$ & $\begin{array}{l}\text { Membros da } \\
\text { Comissão de } \\
\text { Gestão Ambiental e } \\
0 \quad \text { Juridico da } \\
\text { UFPB. }\end{array}$ & $\begin{array}{l}\text { Durante todo o ano } \\
\text { de aplicaçấo }\end{array}$ & Documentos oficiais. \\
\hline $\begin{array}{l}\text { Integração da Comissão de Gestão } \\
\text { Ambiental da UFPB com o Comitê } \\
\text { de Inclusão e Acessibilidade da } \\
\text { UFPB. }\end{array}$ & $\begin{array}{l}\text { Fortalecimento e união dessas } \\
\text { duas comissరెes. }\end{array}$ & $\begin{array}{l}\text { Comissão de Gestão } \\
\text { Ambiental e Comissão de } \\
\text { Inclusão de Acessibilidade. }\end{array}$ & $\begin{array}{l}\text { Membros da } \\
\text { Comissão de } \\
\text { Gestão Ambiental e } \\
\text { Comitê de Inclusão } \\
\text { e Acessibilidade da } \\
\text { UTPB }\end{array}$ & $\begin{array}{l}\text { Primeiro semestre } \\
\text { do ano de aplicação }\end{array}$ & $\begin{array}{l}\text { Documentos oficializados nas } \\
\text { reuniðes }\end{array}$ \\
\hline $\begin{array}{l}\text { Divulgar e aplicar as ações da } \\
\text { acessibilidade Universal, propostas } \\
\text { em conjuntos pelas duas comissōes. }\end{array}$ & $\begin{array}{l}\text { Apresentação das ações e } \\
\text { proposta para toda } \\
\text { comunidade universitária. }\end{array}$ & $\begin{array}{l}\text { Comissão de Gestão } \\
\text { Ambiental e Comissão de } \\
\text { Inclusão de Acessibilidade }\end{array}$ & $\begin{array}{l}\text { Membros da } \\
\text { Comissão de } \\
\text { Gestão Ambiental e } \\
\text { Comitê de Inclusão } \\
\text { e Acessibilidade da } \\
\text { UFPB }\end{array}$ & $\begin{array}{l}\text { Durante todo o ano } \\
\text { de aplicaçio }\end{array}$ & Relatórios, divulgação na midia. \\
\hline
\end{tabular}

\section{Proposta para o manejo dos resíduos orgânicos \\ As atividades agrícolas e a} agropecuárias geram grande quantidade de resíduos, como restos de culturas, palhas e resíduos agroindustriais, dejetos de animais, os quais, em alguns casos, provocam sérios problemas de poluição. Entretanto, quando manipulados adequadamente, podem suprir, com vantagens, boa parte da demanda de insumos industrializados sem afetar adversamente os recursos do solo e do ambiente. O aproveitamento dos resíduos agrícolas, industriais, urbanos e florestais pode ser realizado através de um processamento simples denominado compostagem, em pequena, média e grande escala desde que não causem distúrbios ao meio ambiente e à saúde pública.

Conforme Pereira Neto (1987), o termo compostagem refere-se ao processo predominantemente aeróbio, com a degradação de resíduos orgânicos, no qual ocorre a estabilização biológica dos substratos orgânicos, através da atuação de organismos decompositores. Consiste em um processo de oxidação biológica, ocorrendo a liberação de dióxido de 
carbono e vapor de água (Pereira Neto, 1998). Ocorre em duas fases: 1) quando predominam as reações químicas, geralmente termofílicas; 2) denominada de fase de maturação, é quando ocorre o processo de humificação (Pereira Neto, 1987).

Por meio deste processo, é produzido composto orgânico, o qual pode ser utilizado como adubo orgânico (Zucconi e Bertoldi, 1987).

A compostagem é um processo natural, i.e., degradação de matéria orgânica (decomposição). Este mecanismo refere-se também à manipulação do material pelo homem, o qual elaborou técnicas para acelerar esse processo, promovendo a produção de compostos orgânicos ("adubo orgânico”). Este composto, após estabilizado e higienizado, pode ser utilizado para a produção de diversas culturas vegetais (Zucconi e Bertoldi, 1987). Segue abaixo as vantagens do uso da compostagem, de acordo com Sartori et al. (2012):

- Aumento da saúde do solo - a matéria orgânica compostada se liga às partículas do solo (areia, limo e argila), ajudando na retenção da água e drenagem do solo e melhorando sua aeração;

- Redução da erosão do solo - a matéria orgânica compostada aumenta a capacidade de infiltração de água, reduzindo a erosão;

- Redução de doenças de plantas - o composto aumenta a população de minhocas, insetos e microrganismos desejáveis, estabelecendo um equilíbrio entre as populações e a planta hospedeira;

- Manutenção da temperatura e estabilização do $\mathrm{pH}$ do solo - o composto favorece a atividade biológica no solo;

- Ativação da vida do solo - o composto favorece a reprodução de microrganismos benéficos às culturas agrícolas;
- Aproveitamento agrícola da matéria orgânica - a compostagem diminui a perda econômica ou aumenta o lucro na propriedade rural;

- Processo ambientalmente seguro - a compostagem dos resíduos orgânicos reduz o impacto e a poluição no ambiente;

- Degradação de substâncias inibidoras do crescimento vegetal - na palha in natura existem substâncias responsáveis pela inibição do crescimento vegetal, que são degradadas durante a compostagem;

- Economia de tratamento de efluentes - o composto se solubiliza lentamente e é absorvido pelas plantas, não sendo carregado para o lençol freático;

- Redução do odor - depois de compostados, os dejetos animais não geram mais odor.

Atualmente, no Campus I da UFPB há problemas com o destino final dos resíduos orgânicos (e.g. de restaurantes, lanchonetes, resíduo verde), que não são aproveitados. O resíduo verde (e.g. folhas, galhos) é recolhido pelos funcionários, e na maioria das vezes é literalmente "jogado" na mata, ficando em espaço aberto, apesar de ser adequado a sua inserção em uma área que irá realizar a sua decomposição de forma natural, a grande quantidade acumulada nos mesmos locais traz poluição visual (Figura 5).

Desta forma, a compostagem surge como solução para dar destino adequado ao resíduo orgânico, que pode ser transformado em adubo orgânico e utilizado na manutenção da jardinagem na própria universidade, sendo uma solução economicamente viável e eficientemente ecológica.

O composto orgânico pode ser destinado para a elaboração de hortas ecológicas, manutenção de jardins, como também na técnica de cultura de fitoplâncton (Oliveira e Crispim, 2013), que pode ser alimento para a aquicultura. 


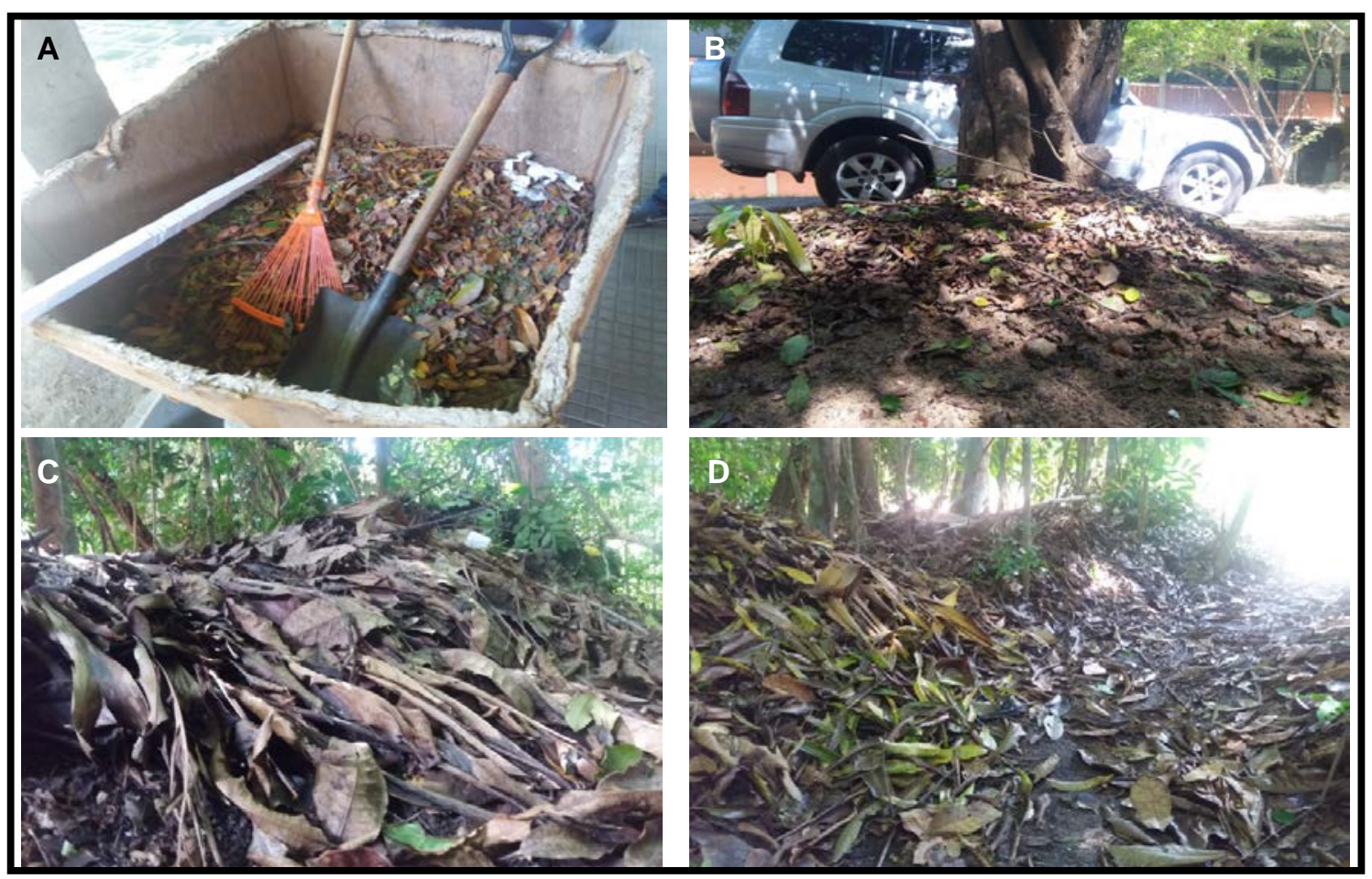

Figura 4. Manejo do resíduo verde produzido no Campus I da UFPB. A, recolhimento realizado pelo funcionário da limpeza; B, folhas depositadas em árvore no estacionamento localizado no Departamento de Química; C, D, folhas colocadas na mata do antigo Biotério do CCEN.

A natureza cíclica dos processos ecológicos é um importante princípio da ecologia. Os laços de realimentação dos ecossistemas são as vias ao longo das quais os nutrientes são continuamente reciclados. Sendo sistemas abertos, todos os organismos de um ecossistema produzem resíduos, mas o que é resíduo para uma espécie é alimento para outra, de modo que o ecossistema como um todo permanece livre de resíduos (Capra, 2004).

\footnotetext{
Proposta de criação de uma Empresa Júnior para manejo dos resíduos orgânicos. As Empresas Juniores são criadas por alunos de cursos de graduação, estando ligadas a um ou mais cursos. A gestão é feita pelos próprios alunos. O principal objetivo destas organizações é promover uma melhor experiência de mercado aos alunos graduandos, fomentando o seu crescimento pessoal e profissional, por meio da oferta de serviços de qualidade e a baixo custo ao mercado.
}

Assim, a implementação de uma empresa júnior na UFPB para a coleta e compostagem dos resíduos orgânicos (e.g. de restaurantes, lanchonetes, resíduo verde) é uma prática que além de minimizar impactos ambientais provocados por estes dejetos, pode gerar um produto de grande valor comercial, o húmus. Assim, os universitários com amplo acesso à informação, têm o dever de incentivar a separação e disseminar a prática da compostagem, para que o produto final seja aproveitado para a criação de hortas orgânicas, bem como, para a própria venda do húmus servindo assim, como adubo orgânico para diversas utilidades. Outro aspecto importante, diz respeito ao caráter pedagógico da proposta, já que o modelo de compostagem é um ótimo exemplo para grupos em educação ambiental e modelo de gestão ambiental, possibilitando sua replicação em outros ambientes.

Dessa forma, a Empresa Júnior iria inicialmente conversar com todos os bares e restaurantes presentes no Campus I, 
incluindo o Restaurante Universitário (RU). Seriam adquiridos tambores plásticos para a coleta dos resíduos e combinada a coleta diária. O Campus I da UFPB possui várias áreas disponíveis que poderiam ser usadas para a produção da composteira. Inicialmente poderiam ser usadas clareiras dentro de áreas da mata (Ex. local do biotério/DSE). Posteriormente poderiam ser selecionados mais espaços, um em cada Centro, para facilitar o transporte dos resíduos. Em cada composteira seriam colocados os resíduos (não precisaria impermeabilizar o solo, porque os nutrientes devem ser aproveitados pela mata presente) e diariamente cobertos por solo local. Seria uma camada de resíduos, uma de solo, até chegar a uma altura em que o manejo não se faça mais possível, daí parte-se para o uso de espaço lateral. Devem ser colocados canos para facilitar a oxigenação do composto, assim como deve ser umedecida umas três vezes por semana, conforme metodologia de Oliveira (2008). O composto seria coberto, para evitar que a chuva retirasse e lixiviasse os nutrientes para não enfraquecer o composto. A composteira deveria ser em formato de um círculo, em que quando se alcançasse $o$ início este já deveria estar pronto para retirar o composto. A Empresa Júnior poderia depois tentar vender o produto, inserindo-se de alguma forma no mercado.

\section{Proposta de monitoramento e controle dos mosquitos vetores \\ O PGLS/UFPB não contempla} ações voltadas para monitoramento e controle de insetos vetores, em especial os mosquitos, cuja ocorrência está intimamente relacionada com o manejo ambiental.

Os insetos podem ser importantes vetores de patógenos, principalmente as fêmeas adultas de alguns grupos de mosquitos (Diptera, Culicidae), que necessitam de proteínas sanguíneas para maturação ovariana (Ohm et al., 2016) e de algum reservatório com água para realização da postura.

Os mosquitos, ao realizarem o repasto sanguíneo, além de causarem incômodo, podem veicular vírus, bactérias e protozoários, o que no caso dos culicídeos ocorre por meio da saliva. Esses organismos são de grande importância para a saúde pública, podem causar mortes e têm sido responsabilizados por inúmeras epidemias que ao longo da história dizimaram algumas populações humanas (Carrera, 1991). Atualmente, cerca de um milhão de pessoas morrem por ano em todo o mundo em decorrência de doenças causadas por microrganismos transmitidos por mosquitos (AMCA, 2017). Dentre os mosquitos vetores, destacam-se os do gênero Aedes, principalmente a espécie Aedes aegypti (Linnaeus in Hasselquist, 1762), responsável pela transmissão de dengue, febre amarela, zika e chikungunya em áreas urbanas do Brasil.

Propõe-se a inclusão de medidas quanto aos mosquitos vetores por meio de busca e eliminação de focos, monitoramento da ocorrência dos mosquitos vetores, bem como a sensibilização das pessoas por meio de educação ambiental.

Sendo a universidade um local de intensa circulação de pessoas, sejam alunos, professores, servidores ou visitantes, bem como o grande número de casos das viroses relacionadas com o mosquito, propõe-se como necessária a inclusão de um programa sistemático para realização de buscas por possíveis ou potenciais focos (criadouros) de mosquitos vetores na UFPB, como as bromélias, vasos, garrafas, copos descartáveis, lixo em geral, caixas d'água, tanques, telhados, calhas, entre outros (Figura 5). Deverão ser procurados, examinados e eliminados possíveis focos em recipientes que possam servir como criadouros do mosquito Ae. aegypti na área da UFPB, sejam setores de aula, áreas de convivência, lanchonetes, restaurantes e áreas verdes, entre outras. 


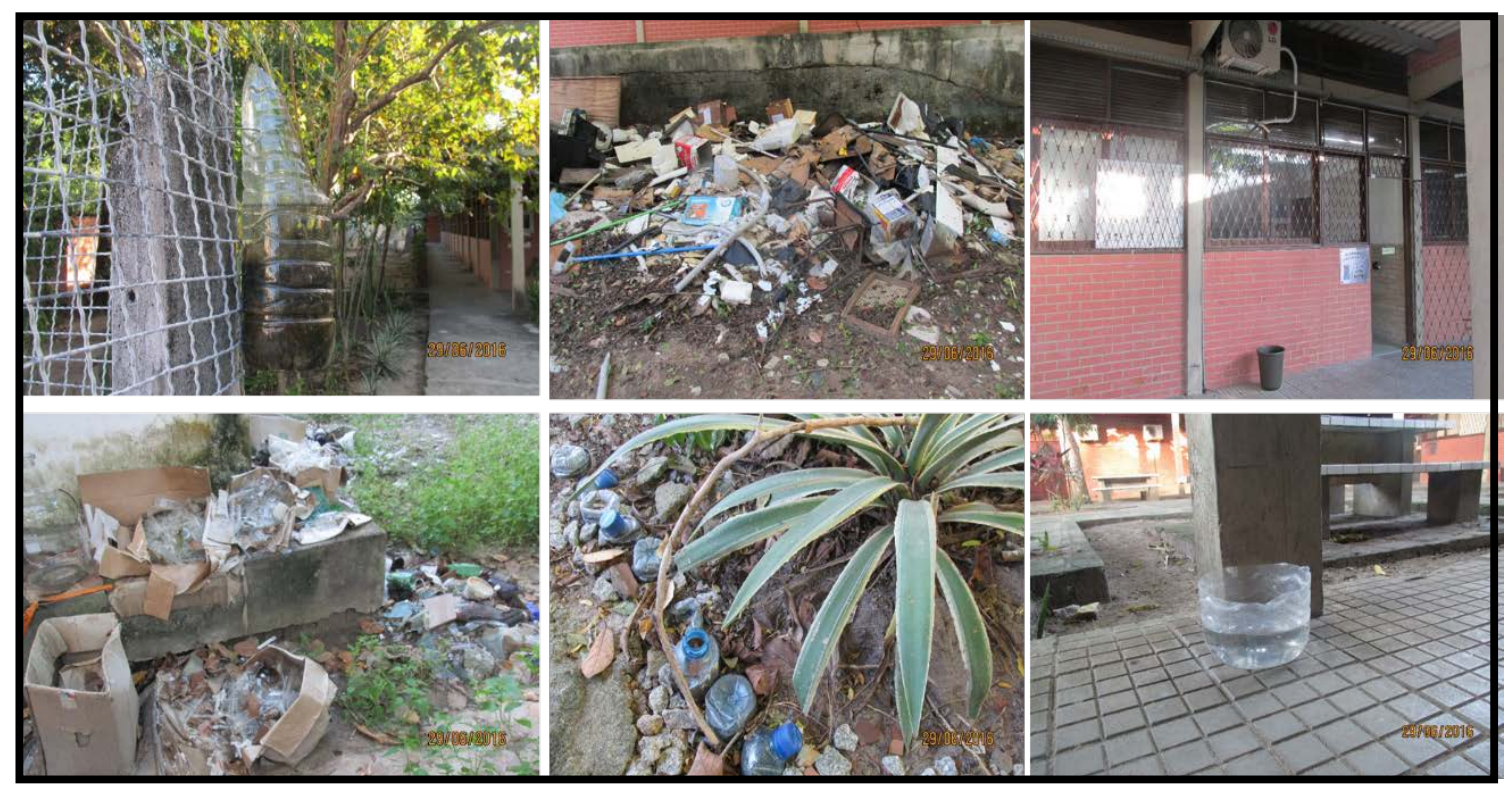

Figura 5. Potenciais focos para reprodução do mosquito Ae. aegypti no Campus I da UFPB/Centro de Ciências Exatas e da Natureza.

Monitoramento dos vetores pode ser realizado por meio da utilização sistemática de ovitrampas (Figura 6) nas áreas do Campus para contagem e eliminação de ovos, com consequente conhecimento das áreas prioritárias para busca de focos.

As ovitrampas sugeridas para monitoramento e controle apresentam grande especificidade e são usadas na vigilância entomológica de Ae. aegypti com vistas à elaboração de índices de infestação (Brasil, 2014). Consistem em um vaso preto com água e uma palheta em "Eucatex" onde a fêmea coloca os ovos (Figura 6). A palheta deve ficar exposta no ambiente por três dias, quando deverá ser retirada para contagem dos ovos. É importante ressaltar que a presença de muitos ovos indica possíveis focos na área monitorada, devendo ser realizadas buscas para eliminação dos mesmos.

O uso de ovitrampas é importante porque por serem locais vigiados e manejados servirão como armadilhas para a postura, visto que os ovos serão colocados lá e posteriormente eliminados. Outra proposta é o uso de áreas em que se possam colocar peixes, assim as fêmeas depositam seus ovos e as larvas serão comidas pelos peixes, evitando que na ausência de água, achem locais mais escondidos, de difícil acesso e que tenham sucesso na postura.

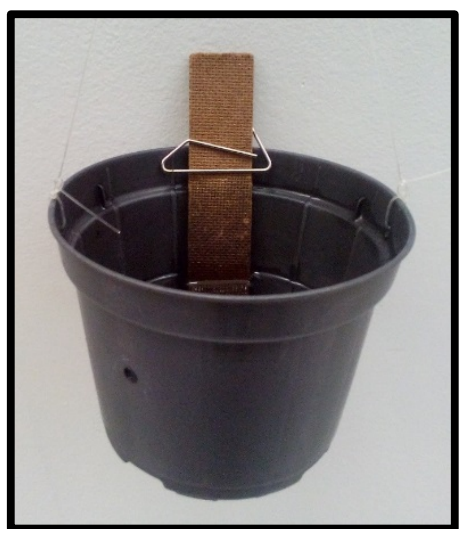

Figura 6. Ovitrampa.

Deverão ainda ser realizadas ações de educação ambiental, buscando sensibilizar a comunidade universitária quanto ao conhecimento sobre mosquito, destino de resíduos e eliminação de possíveis focos. Tais ações podem abranger inicialmente reuniões para definição de estratégias que poderão conter cartazes dispostos em locais estratégicos, propagandas nos sites da universidade, 
incentivo para que professores mencionem a problemática em sala de aula, trotes educativos, entre outras ações.

Mostra-se, portanto, como relevante, e é proposto neste trabalho, a inserção de práticas voltadas para o monitoramento e controle dos mosquitos vetores na área da UFPB, práticas essas de grande importância, uma vez que podem resultar na mitigação de riscos aos quais a comunidade universitária é exposta diariamente nas dependências da universidade.

\section{Proposta de zoneamento para o campus I da UFPB}

A questão ambiental há muito tempo tem tido enorme repercussão tanto no cenário nacional quanto no internacional, em decorrência do consenso da população mundial sobre a necessidade de preservação do meio ambiente. A Constituição da República Federativa do Brasil, em seu art. 255 (Brasil, 1988), trata o meio ambiente ecologicamente equilibrado, como um direito transindividual, ou seja, um direito que abrange a todos os seres humanos, e ao mesmo tempo a cada indivíduo.

Além disso, a relevância sobre o tema originou uma legislação mais rígida sobre as questões ambientais, visando coibir práticas abusivas contra o meio ambiente.

Estudos relacionados sobre o uso dos recursos naturais pelo homem vêm fornecendo suporte instrumental para a construção de novos padrões de sustentabilidade como, por exemplo, o uso e cobertura do solo, visando a melhorar ou a sugerir propostas de planejamento a sustentabilidade desses locais, assim como para delimitar áreas prioritárias para conservação (Faria et al., 2012).

A Política Nacional do Meio Ambiente, instituída pela Lei $n^{\circ}$ 6.938/1981 (Brasil, 1981), instrumentaliza o zoneamento ambiental, tornando-se essencial nesta temática. Este instrumento consiste na divisão de determinado território em áreas onde "se autorizam determinadas atividades ou restringe-se, de modo absoluto ou relativo, o exercício de outras” em razão das características ambientais e socioeconômicas do local (Brasil, 1981).

A ideia de zoneamento não é nova no Brasil. Desde o Estatuto da Terra de 1964 (Lei no 4.504/1964) (Brasil, 1964) até o atual Estatuto da Cidade de 2001 (Lei ${ }^{\circ}$ 10.257/2001) (Brasil, 2001), passando por leis que se referem ao planejamento de áreas de interesse turístico, entorno de aeroportos, unidades de conservação, preservação de vegetação nativa em propriedades rurais, proteção de bacias hidrográficas, seguro agrícola, localização de indústrias.

O conceito de zoneamento tem origem nas sociedades industrializadas e urbanizadas e na necessidade do estabelecimento de áreas com destinação especial.

Além do zoneamento ambiental, que após o Decreto $n^{\circ}$ 4.297/2002 (Brasil, 2002), passou a ser chamado de zoneamento ecológico-econômico (ZEE), outros tipos de zoneamento são destacados, dentre esses zoneamentos, podem ser mencionados:

-Zoneamento socioeconômico-ecológico (ZSEE);

- Zoneamento agroecológico (ZAE);

- Zoneamento agrícola de risco climático;

- Zoneamento industrial;

- Zoneamento urbano; e

- Etnozoneamento.

De acordo com a análise realizada no PGLS pela Comissão de Gestão Ambiental da UFPB, foi verificada a ausência de informações cartográficas, bem como do uso de ferramentas de geotecnologias na confecção deste plano.

Com a aplicação dessas ferramentas, principalmente no que tange à gestão dos resíduos da UFPB, pode-se conseguir uma melhor logística de rotas, locação de depósitos de acondicionamento e armazenamento dos resíduos comuns e perigosos da instituição e identificação das fontes geradoras.

Por meio do exposto, faz-se necessário a espacialização das informações 
do uso e ocupação do solo do Campus I da UFPB, sendo assim, este artigo apresenta uma proposta para a criação e execução de um zoneamento (Figuras 7, 8 e 9). Como resultados, verifica-se que a área total do
Campus I é 108 ha, sendo a vegetação com área de 47 ha, área de esporte com 6,2 ha, e salas de aula/secretarias/bibliotecas com 21 ha.

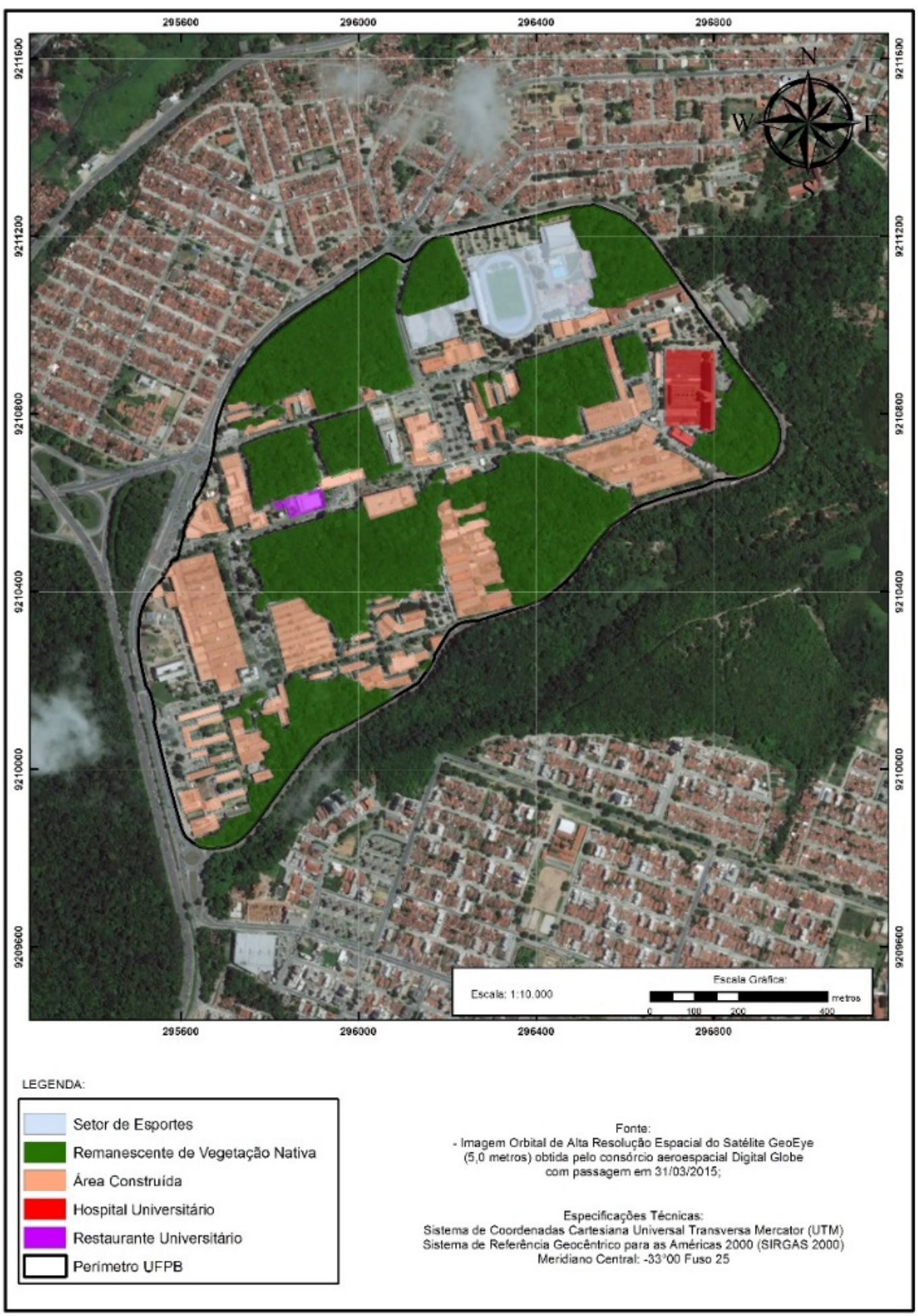

Figura 7. Proposta de zoneamento (geral) para o Campus I da Universidade Federal da Paraíba. 


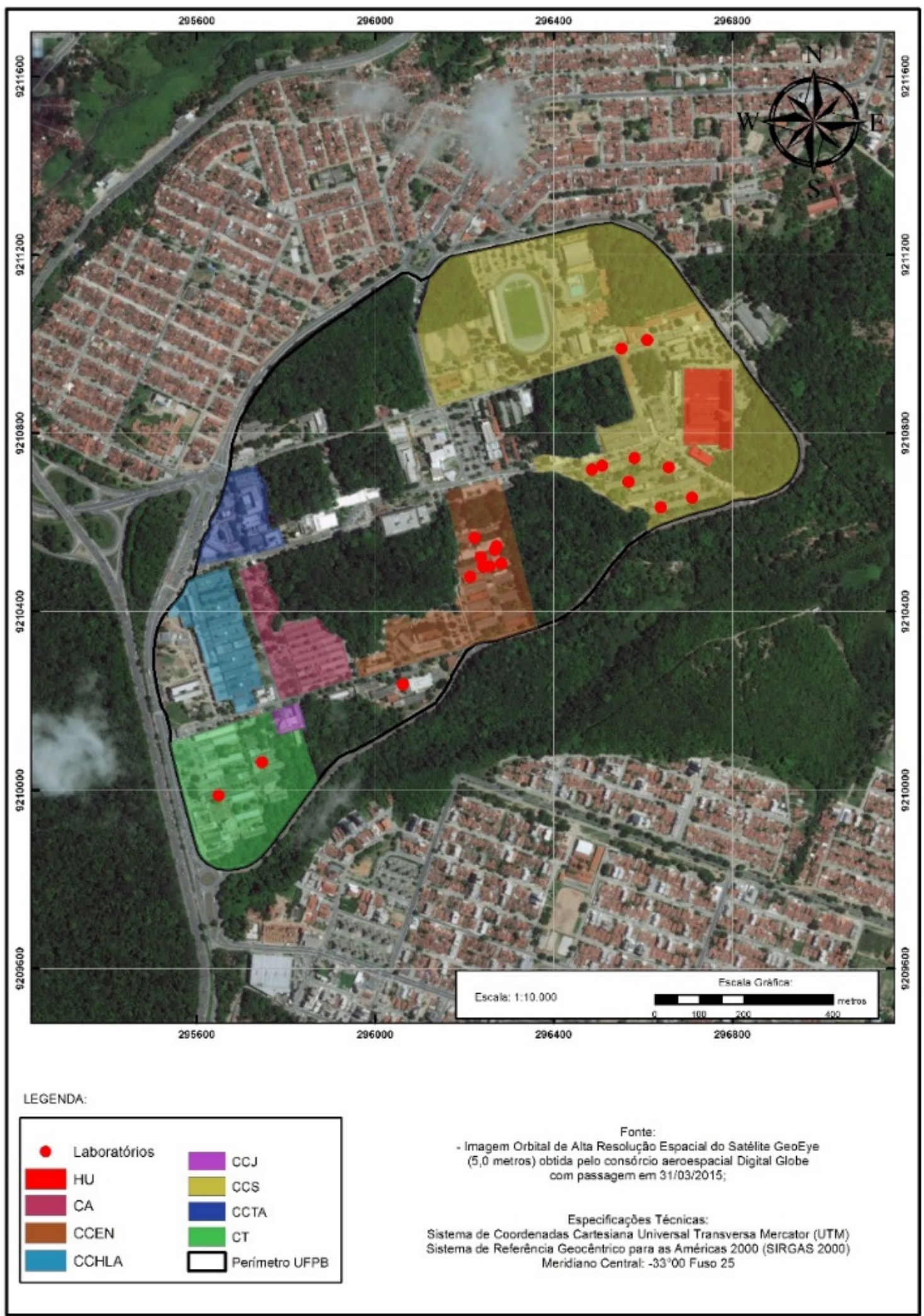

Figura 8. Proposta de zoneamento para o Campus I da Universidade Federal da Paraíba, destacando-se os principais laboratórios que produzem resíduos. HU (Hospital Universitário); CA (Central de aulas); CCEN (Centro de Ciências Exatas e da Natureza); CCHLA (Centro de Ciências Humanas, Letras e Artes); CCJ (Centro de Ciências Jurídicas); CCS (Centro de Ciências da Saúde); CCTA (Centro de Comunicação, Turismo e Artes); CT (Centro de Tecnologia). 


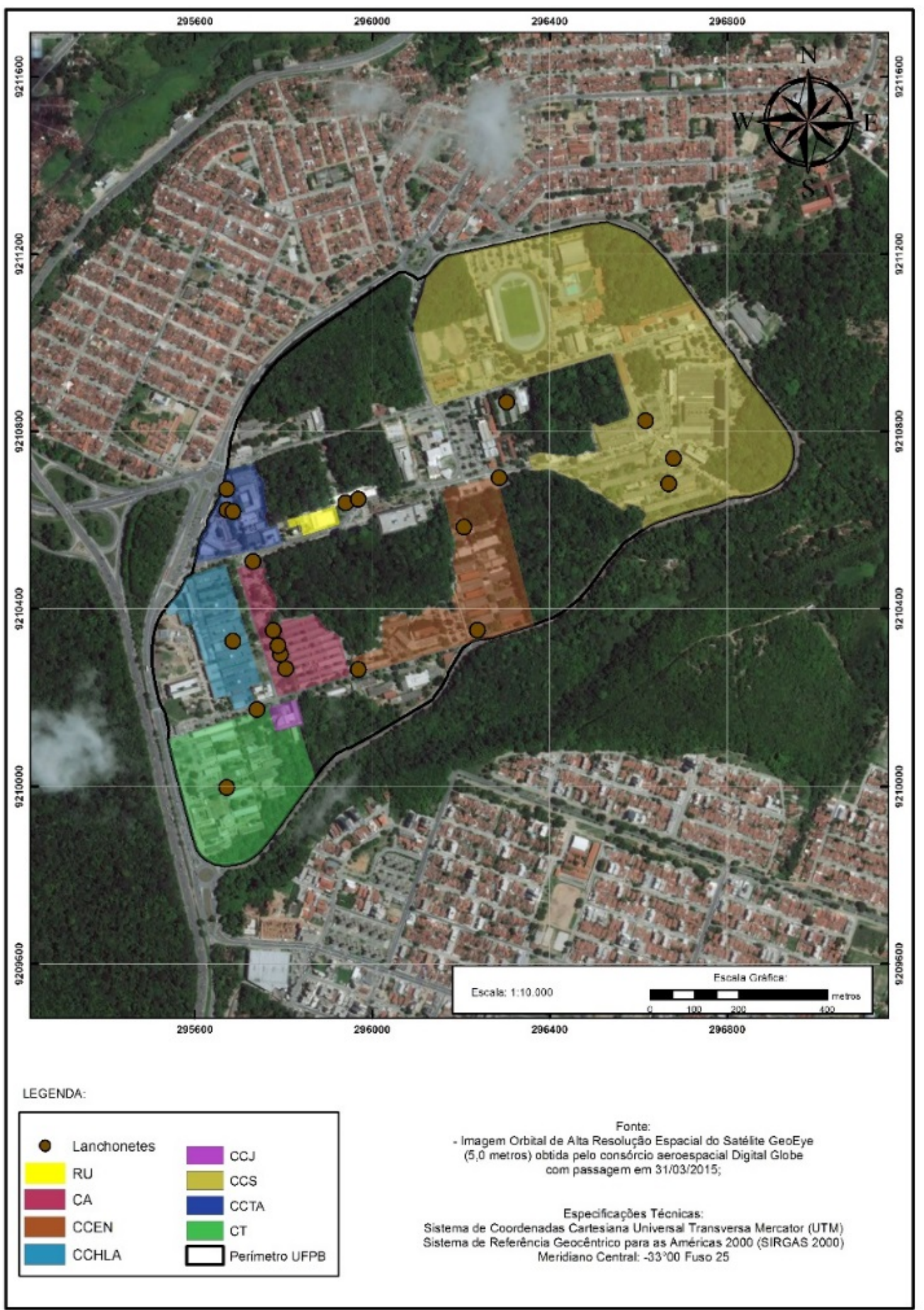

Figura 9. Proposta de zoneamento para o Campus I da Universidade Federal da Paraíba, destacando-se as lanchonetes. 


\section{Conclusão}

O presente estudo apresentou propostas para complementar o Plano de Gestão Ambiental do Campus I da UFPB, como um projeto de acessibilidade para melhoria na mobilidade humana de portadores de deficiência física; um programa de manejo dos resíduos orgânicos por meio da compostagem, sendo seu produto aproveitado como fertilizante e utilizado na universidade como solução viável e ecológica, juntamente com a implantação de uma empresa júnior para gerir esse processo; inclusão de medidas quanto aos mosquitos vetores por meio de busca e eliminação de focos, monitoramento da ocorrência, bem como a sensibilização das pessoas por meio de educação ambiental; além de uma proposta de zoneamento por meio da espacialização das informações do uso e ocupação do solo.

\section{Agradecimentos}

Agradecemos ao apoio institucional fornecido pela Universidade Federal da Paraíba, Programa de Pós-Graduação em Desenvolvimento e Meio Ambiente (PRODEMA). DAC agradece pela bolsa de doutorado fornecida pela Fundação de Apoio à Pesquisa do Estado da Paraíba (FAPESQ), em parceria com a Coordenação de Aperfeiçoamento de Pessoal de Nível Superior (CAPES). RSAM e MLFS agradecem pela bolsa de mestrado fornecida pela CAPES/Brasil.

\section{Declaração de conflito de interesses}

Os autores declaram não haver conflito de interesses.

\section{Referências}

ABNT - Associação Brasileira de Normas Técnicas. ABNT NBR 9050: acessibilidade a edificações, mobiliário, espaços e equipamentos urbanos. Rio de Janeiro: ABNT, 2004.

AESA - Agência Executiva de Gestão das Águas do Estado da Paraíba. 2016. Disponível em: <http://www.aesa.pb.gov.br/>. Acesso em: 16 nov. 2016.

AMCA - American Mosquito Control Association. Mosquito-borne diseases. 2017. Disponível em: <http:/www.mosquito.org/ mosquito-borne-diseases>. Acesso: 6 fev. 2017.

Barbieri, J. C. Gestão Ambiental Empresarial: conceitos, modelos e instrumentos. São Paulo: Saraiva, 2004.

Bing Maps. 2016. Disponível em: <https://www.bing.com/maps/>. Acesso em: 16 nov. 2016.

Brasil. Lei $n^{0}$ 4.504, de 30 de novembro de 1964. Dispõe sobre o Estatuto da Terra, e dá outras providências. Disponível em: <http://www.planalto.gov.br/ccivil_03/leis/L450 4compilada.htm>. Acesso em: 02 jan. 2017.

Brasil. Lei $\mathrm{n}^{\circ}$ 6.938, de 31 de agosto de 1981 . Dispõe sobre a Política Nacional do Meio Ambiente, seus fins e mecanismos de formulação e aplicação, e dá outras providências. Disponível em: $<$ http://www.planalto.gov.br/ccivil_03/leis/L693 8.htm>. Acesso em: 02 jan. 2017.

Brasil. Constituição da República Federativa do Brasil de 1988. Disponível em: $<$ http://www.planalto.gov.br/ccivil_03/Constitui cao/Constituicao.htm>. Acesso em: 05 jan. 2017.

Brasil. Lei no 9.433, de 8 de janeiro de 1997. Institui a Política Nacional de Recursos Hídricos, cria o Sistema Nacional de Gerenciamento de Recursos Hídricos, regulamenta o inciso XIX do art. 21 da Constituição Federal, e altera 0 art. $1^{\circ}$ da Lei $n^{\circ}$ 8.001, de 13 de março de 1990, que modificou a Lei $n^{\circ}$ 7.990, de 28 de dezembro de 1989. Disponível em: <http://www.planalto.gov.br/ ccivil_03/leis/L9433.htm>. Acesso em: 08 fev. 2017.

Brasil. Lei $\mathbf{n}^{\circ}$ 10.257, de 10 de julho de 2001. Regulamenta os arts. 182 e 183 da Constituição Federal, estabelece diretrizes gerais da política urbana e dá outras providências. Disponível em: <http://www.planalto.gov.br/ccivil_03/leis/LEIS _2001/L10257.htm>. Acesso em: 08 fev. 2017.

Brasil. Decreto $n^{0}$ 4.297, de 10 de julho de 2002. Regulamenta o art. $9^{\circ}$, inciso II, da Lei $n^{\circ}$ 6.938, de 31 de agosto de 1981, estabelecendo critérios para o Zoneamento EcológicoEconômico do Brasil - ZEE, e dá outras providências. Disponível em: <http://www.planalto.gov.br/ccivil_03/decreto/2 002/d4297.htm>. Acesso em: 08 fev. 2017. 
Brasil. Decreto $\mathbf{n}^{0}$ 5.296, de 2 de dezembro de 2004. Regulamenta as Leis $n^{o s} 10.048$, de 8 de novembro de 2000, que dá prioridade de atendimento às pessoas que especifica, e 10.098, de 19 de dezembro de 2000, que estabelece normas gerais e critérios básicos para a promoção da acessibilidade das pessoas portadoras de deficiência ou com mobilidade reduzida, e dá outras providências. Disponível em: <http://www.planalto.gov.br/ccivil_03/ _ato2004-2006/2004/decreto/d5296.htm>.

Acesso em: 11 jan. 2017.

Brasil. Instrução Normativa MPOG $n^{\circ}$ 01, de 19 de janeiro de 2010. Dispõe sobre os critérios de sustentabilidade ambiental na aquisição de bens, contratação de serviços ou obras pela Administração Pública Federal direta, autárquica e fundacional e dá outras providências. Disponível em: $<$ http://www.comprasnet.gov.br/legislacao/legis lacaoDetalhe.asp?ctdCod=295>. Acesso em: 11 jan. 2017.

Brasil. Lei $\mathrm{n}^{\circ}$ 12.305, de 2 de agosto de 2010. Institui a Política Nacional de Resíduos Sólidos; altera a Lei $\mathrm{n}^{0}$ 9.605, de 12 de fevereiro de 1998; e dá outras providências. Disponível em: $<$ http://www.planalto.gov.br/ccivil_03/_ato2007 -2010/2010/lei/l12305.htm>. Acesso em: 11 jan. 2017.

Brasil. Decreto $\mathbf{n}^{\mathbf{0}}$ 7.746, de 5 de junho de 2012. Regulamenta o art. $3^{\circ}$ da Lei $n^{\circ} 8.666$, de 21 de junho de 1993, para estabelecer critérios, práticas e diretrizes para a promoção do desenvolvimento nacional sustentável nas contratações realizadas pela administração pública federal, e institui a Comissão Interministerial de Sustentabilidade na Administração Pública - CISAP. Disponível em: <http://www.planalto.gov.br/ccivil_03/_ato2011 -2014/2012/decreto/d7746.htm>. Acesso em: 16 jan. 2017.

Brasil. Nota Técnica $n^{0}$ 3/2014/IOCFIOCRUZ/Diretoria, de 22 de maio de 2014. Avaliação de armadilhas para a vigilância entomológica de Aedes aegypti com vistas à elaboração de novos índices de infestação. Disponível em: <http://www.fiocruz.br/ioc/ media/nota_tecnica_ioc_3.pdf $>$. Acesso em: 16 jan. 2017.

Brasil. Lei no 13.146, de 6 de julho de 2015. Institui a Lei Brasileira de Inclusão da Pessoa com Deficiência (Estatuto da Pessoa com Deficiência). Disponível em: $<$ http://www.planalto.gov.br/ccivil_03/_Ato201 5-2018/2015/Lei/L13146.htm>. Acesso em: 06 jan. 2017.
Capra, F. A. A teia da vida: uma nova compreensão científica dos sistemas vivos. São Paulo: Pensamento, 2004.

Carrera, M. Insetos de interesse médico e veterinário. Curitiba: Editora UFPR, 1991.

CGA - Comissão de Gestão Ambiental. Plano de Gestão de Logística Sustentável PGLS/UFPB (2013-2015). João Pessoa: Universidade Federal da Paraíba, 2013.

CGA - Comissão de Gestão Ambiental. Relatório preliminar do Plano de Gestão de Logística Sustentável (Out. 2013-Mar. 2014). João Pessoa: Universidade Federal da Paraíba, 2015.

Coelho, C.; Lacerda, C. S.; Gadelha, D. P.; Barbosa, E. U. G.; Lira, E. H. A.; Mendonça, J. D. L.; Oliveira, R. S.; Paz, R. J.; Cavalheiro, T. B.; Silva, T. C. F.; Souza, T. S. P. Sustentabilidade da atividade turística do Delta do Parnaíba, Estado do Piauí, Nordeste do Brasil. Revista Brasileira de Gestão Ambiental e Sustentabilidade, v. 4, n. 8, p. 263-288, 2017. https://doi.org/10.21438/rbgas.040803

Faria, K. M. S.; Siqueira, M. N.; Carneiro, G. T.; Castro, S. S. Análise geoecológica da conservação ambiental das sub-bacias do Rio Claro (GO) e do Rio Garças (MT). Revista Nordestina de Ecoturismo, v. 5, n. 1, p. 111118, 2012. Disponível em: $<$ http://sustenere.co/journals/index.php/nature/ar ticle/view/ESS1983-8344.2012.001.0012/142>. Acesso em: 16 jan. 2017.

Keinert, T. M. M. Organizações sustentáveis: utopias e inovações. São Paulo: Annablume; Belo Horizonte: Fapemig, 2007.

Leff, E. Epistemologia Ambiental. São Paulo: Cortez, 2001.

Lira, D. Acessibilidade na educação superior: novos desafios para as universidades. Resumos do X ANPED Sul, Florianópolis, 2014. Disponível em: <http://xanpedsul.faed.udesc.br/ arq_pdf/659-0.pdf $>$. Acesso em: 11 jul. 2016.

Nunes, L. A.; Lima, D. C. R.; Valques, I. J. B.; Soares, P. F. Acessibilidade e inclusão social no Campus da Universidade Estadual de Maringá/PR. Resumos do XXXV Congresso Brasileiro de Educação em Engenharia, Curitiba, 2007. Disponível em: $<$ http://www.abenge.org.br/CobengeAnteriores/ 2007/artigos/384-Diana Carla Rodrigues Lima.pdf $>$. Acesso em: 11 jan. 2017.

Ohm, J. R.; Teeple, J.; Nelson, W. A.; Thomas, M. B.; Read, A. F.; Cator, L. J. Fitness consequences of altered feeding behavior in immune-challenged mosquitoes. Parasites \& 
Vectors, v. 9, n. 113, p. 1-10, 2016. https://doi.org/10.1186/s13071-016-1392-x

Oliveira, F. M. F. Cultivo de plâncton para uso em aqüicultura: proposta de desenvolvimento de atividade econômica sustentável, para a comunidade pesqueira da praia da Penha - João Pessoa, Brasil. João Pessoa: Universidade Federal da Paraíba, 2008. (Dissertação de mestrado).

Oliveira, F. M. F.; Crispim, M. C. Aquicultura sustentável como forma alternativa de minimizar os impactos desta produção em comunidades pesqueiras. Gaia Scientia, v. 7, n. 1, p. 64-79, 2013. Disponível em: <http://periodicos.ufpb.br/ojs/index.php/gaia/art icle/download/18021/10237>. Acesso em: 07 fev. 2017.

Pereira Neto, J. T. On the treatment of municipal refuse and sewage sludge using aerated static pile composting: a low cost technology approach. Leeds: University of Leeds, 1987. (Tese de doutorado).
Pereira Neto, J. T. Lixo urbano no Brasil: descaso, poluição irreversível e mortalidade infantil. Revista Ação Ambiental, v. 1, n. 1, p. 8-11, 1998.

Sartori, V. C.; Ribeiro, R. T. S.; Pauletti, G. F.; Pansera, M. R.; Rupp, L. C. D.; Venturin, L. Cartilha para agricultores (compostagem): produção de fertilizantes a partir de resíduos orgânicos. Caxias do Sul: Universidade de Caxias do Sul, 2012.

UFPB - Universidade Federal da Paraíba. Comissão de Gestão Ambiental. 2017. Disponível em: <http://www.ufpb.br/cga> Acesso em: 07 fev. 2017.

Zucconi, F.; Bertoldi, M. Composts specifications for the production and characterization of composts from municipal solid waste. In: De Bertoldi, M.; Ferranti, M .P.; L'Hermite, P.; Zucconi, F. (Eds.). Compost: production, quality and use. Londres: Elsevier Applied Science, 1987. p. 30-50.

Informação da Licença: Este é um artigo Open Access distribuído sob os termos da Licença Creative Commons Attribution, que permite uso irrestrito, distribuição e reprodução em qualquer meio, desde que a obra original seja devidamente citada. 